\title{
THE ACCEPTABLE FACE OF INTERVENTION: Intellectual Property in Posnerian LAW AND ECONOMICS $^{1}$
}

\author{
DAVID CAMPBELL \\ Department of Law, University of Durham, $U K$ \\ SOL PICCIOTTO \\ School of Law, Lancaster University, UK
}

\begin{abstract}
INTRODUCTION
Over their long and incredibly prolific publishing careers, William Landes and Richard Posner (hereinafter L\&P) have independently and jointly published what for mere mortals would be a large number of papers on intellectual property (hereinafter IP). Nevertheless, IP evidently is only a relatively minor interest to Posner. He has published merely 20 or so substantial papers on it, about half of which were written with Landes (pp 3-4), whereas his total output now runs to about 300 books and substantial papers, written at a rate of almost 10 a year since 1969 , and during this time he has also written some 150 other pieces and served as an appeal court judge. In The Economic Structure of Intellectual Property Law, L\&P have now brought together and reworked many of their papers on IP ( $p$ 425) to give the most extensive commentary upon it from the 'Posnerian' law and economics perspective. With the striking exception of a sustained treatment of the unusual remedies extended to the protection of IP (p 7), most of the issues raised by IP are somewhere discussed in the papers now combined in this book, and a, to some extent new, framework for this discussion is given at the beginning of the book. The gist of L\&P's position is that, though they to some extent agree with the widely-held belief that copyright holders in particular (chs 2-3), but also patent holders to a lesser extent (pp 310-26), now enjoy excessive rights ( $\mathrm{p} 9$ ), they generally approve of intellectual property: 'We do ? find pretty solid economic support for a degree of trade secrecy protection close to what we have and for a degree of copyright and patent protection as well, but possibly a lesser degree than we have' ( $\mathrm{p} 9$ ).

In this review we will argue that L\&P's defence of intellectual property is not reconcilable with the stance they have elsewhere taken towards government intervention. IP rights are government interventions in market allocations, and their justification is in terms of optimising the social welfare function. As such they should be subject to many of the criticisms L\&P have levelled at other interventions, but they are not. Reflection on this paradox leads to interesting insights into the nature of Posnerian 'efficiency' and 'welfare maximisation'. More broadly, it once again illustrates the way in which Posnerian law and economics is an interaction of mutually reinforcing economic and legal formalisms (Campbell and Picciotto 1998). A truly critical approach to both the law and the economics of IP could contribute to a fundamental re-evaluation of the social consequences of IP law, especially as it has developed in the recent past, and to some radical proposals for change. But L\&P merely apply a hackneyed formula to yet another body of law, and so provide no more than a few ideas for tinkering with details of IP; despite being, as we will see, conscious that the entire edifice rests on the weakest of foundations.
\end{abstract}




\section{L\&P'S ARGUMENT FOR IP}

As the title of their book, and, of course, the nature of their entire work, leads one to expect, L\&P's account of IP law is economic. Quickly dismissing 'Other perspectives ... besides the economic' ( $\mathrm{p} 4), \mathrm{L} \& \mathrm{P}$ put forward 'an analysis and evaluation of intellectual property law ? conducted within an economic framework that seeks to align that law with the dictates of economic efficiency' (p 4). As with their earlier work on eg tort law (p 10, cf Landes and Posner 1987), L\&P's aim is to cut through the complexities of the legal doctrines to enhance understanding of the "economic structure' of IP, revealing the 'deep commonality, as well as significant differences, among the various fields of intellectual property law, and between intellectual property law and the law governing physical property' (p10).

But whereas L\&P are confident that their work on tort does show a 'generally efficient' 'unity' to the law it studies, they concede from the start that IP does not have such a unity, and consequently there is a 'degree to which economic analysis of intellectual property remains inconclusive, if not indeterminate' (p10). Consequently, in order to bring such unity and structure to the field as is possible, they promise a novel departure from the standard economic argument for IP. That argument is, of course, that the state is required to grant IP 'monopolies' because, in their absence, the 'intangible' nature of IP makes it difficult to exclude non-paying use, and without the ability to charge for use, there will be insufficient incentive to innovate, so the rate of innovation will be too low. We will call this the 'innovation argument'. L\&P, however, tell us that:

It may come as a surprise to many readers that the economic arguments we make for intellectual property protection are not based primarily on a belief that without legal protection the incentives to create such property would be inadequate. That belief cannot be defended confidently on the basis of current knowledge. The concerns we highlight have rather to do with such things as optimal management of existing stocks of intellectual property, congestion externalities, search costs, rent-seeking, and transaction costs (pp 9-10).

Throughout their book, L\&P do indeed highlight subsidiary aspects of the case for IP. The patent, for example, is defended on the basis that, in its absence, "investors would invest many more resources in maintaining trade secrecy (and competitors in unmasking them) and inventive activity would be inefficiently biased toward inventions that can kept secret' ( $p$ 328). 'Moral rights' (in their US form at least) are criticised because 'much of what they seek to prevent is already forbidden, often by criminal as well as civil law' (p 276), and the mischiefs they alone seek to address are 'too rare to justify the creation and maintenance of a complex body of law (with undesirable side-effects) designed to prevent them arising' (p 280). One could go on for this book does make provocative comments about many of the current lively policy issues within IP law. In particular, its remarks on 'congestion effects' (pp 2228) are, we believe, an unarguably interesting contribution.

But when it comes to the basic issue raised by IP law, which is whether it is justified at all, L\&P are committed to the innovation argument. This is the core of 'The Economic Theory of Property' set out in Chapter 1, and recapitulated at points throughout the book. Their basic account is so conventional that it does not seem worthwhile to set it out in full, and, in truth, there does not seem to be much substance to their claim to be stating a novel economic argument for IP. Instead, they place equivocation about the innovation theory at the heart of their account of that theory. 
L\&P repeatedly tell us that IP rights have 'social costs' ( $p$ 172), that the argument for the necessity of IP rights for innovation to take place is 'easily exaggerated' (p 53), that it would be a mistake to take the growth in the use of IP rights to be 'a reliable proxy for technological advance' ( $p$ 352), etc; and, in sum, they emphasise a 'costbenefit tradeoff' (p 21) 'between "incentive" and "access", (p 11) in their statement of the innovation theory.

But, although the preposterous partiality of much pleading in IP cases, and of most public debate when yet greater rights are sought, would hardly lead one to realise it, the interesting literature on IP is already dominated by the realisation that the curtailing of IP rights by fair use exceptions, limitations of time and extent, de facto permission for wholesale violation, etc is essential to maintain any plausibility in the argument that granting those rights enhances welfare. L\&P are merely placing these limitations at the heart of their account of the innovation argument. By focusing on partial aspects of the innovation argument and by registering all sorts of caveats about it, it appears that L\&P are taking a distance from that argument, but, with respect, they are merely stating the argument in a less than scrupulous manner. They do not defend that argument outright, but they do basically maintain it, and actually shield it from criticism by treating the counter-evidence as caveats which leave the basic argument intact.

All this is an instance of the 'exception barring' which Lakatos (1978, ch 1) has told us is used to excess in the defence of degenerate research programmes. L\&P plausibly argue that the passage of the US Copyright Act in 1976 marks a step change in the long history of IP, and we are now in period of unprecedented, tremendous growth in IP rights (pp 2-3, 403-4, 406-7). Of this they say: 'Whether the increases in the legal protection of intellectual property since 1976 have conferred net benefits on the US economy is uncertain' ( $\mathrm{p} 416$ ). Now, whilst arguments of this exception barring sort are hardly unknown in Posner's previous work (Campbell and Picciotto, 1998, pp 255-6), this is strikingly theoretically unscrupulous. For anyone who believes that government intervention should be eschewed unless it can reliably be shown to have net social benefits, being uncertain about the net benefits of IP should lead to nothing less than a call for its repeal, but L\&P treat it as merely a qualification of their basically approving stance. They conclude that 'definitive recommendations for fundamental change [to the existing law of IP] cannot be supported on the basis of existing knowledge' (p 10), which is a marked, and markedly curious, reversal of Posner's normal stance towards bodies of the law which cannot be shown to be efficient.

Another consideration makes it even more difficult to see why L\&P would display this commitment to the innovation argument. Very commonly the IP rights they are defending when they accept the innovation argument are regarded as monopolies, and as such, one would have thought, anathema to the 'pro-market' stance of Posnerian law and economics. It is to the resolution of this paradox that this review now turns.

\section{IP AND ANTITRUST}

It can hardly be denied that 'Many important antitrust cases have involved intellectual property' ( $\mathrm{p}$ 372), and indeed there now is a very considerable body of law in which 'the rights of owners of intellectual property have been shaped (mostly limited) to a great degree by antitrust law' ( $p$ 372). Important parts of this body of law are reviewed in Chapter 14, in the course of which L\&P's view of the relationship of IP and antitrust emerges. This attitude is very sympathetic indeed to the IP side of this 
relationship. It will not do to attack IP protection simply by exploiting the 'persuasive definition' (Stevenson 1938) of IP rights as monopolies, trusting to the pejorative connotation of 'monopoly' to prejudice the evaluation of those rights. (One might, however, feel that those proselytisers of IP who so commonly use 'piracy' and similar terms intending to benefit from the opposite connotation can hardly complain about this). However, when L\&P argue that it is 'a mistake' 'to suppose that there is an inherent tension between intellectual property law, because it confers "monopolies", and antitrust law' (p 374), they are purporting to make rather more than this good point.

L\&P sometimes even seem to go so far as to say that IP rights can never productively be described as monopolies at all: 'Talk of patent and copyright "monopolies" is conventional ? This usage is harmless as long as it is understood to be different from how the same word is used in antitrust analysis' ( $p$ 374). The IP right merely creates private property in intangible goods just as, say, land law creates it in tangible goods:

One does not say that the owner has a parcel of land has a monopoly because he has the right to exclude others from using this land. But a patent or a copyright is a monopoly in the same sense. It excludes other people from using some piece of intellectual property without consent. That in itself has no antitrust significance (p 374).

This is right in itself, but it is very partial, for one would have thought that, though they both create private property, it could not be denied that IP rights are created in a very different way to rights in land. But this is just what L\&P do deny. ${ }^{2}$ In what in our opinion remains the most penetrating exposition and evaluation of the innovation argument, Plant (1974, pt 2; see further Picciotto and Campbell 2003, pp 284-91) argued as long ago as 1934-5 that, as L\&P have it, 'intellectual property rights create scarcity whereas property rights in physical goods manage scarcity' ( $p$ 20). Although they initially seem to accept this point made by 'the invaluable Plant' (p 8), they ultimately reject it, claiming that:

[Plant's] point is incomplete. Unless there is a power to exclude, the incentive to create intellectual property in the first place may be impaired. Socially desirable investments ? may be deterred if the creators of intellectual property cannot recoup their sunk costs? charging a price for an [IP right] reduces access to it (a social cost), making it artificially scarce (Plant's point), but increases the incentive to create it in the first place, which is a possibly offsetting social benefit? Arnold Plant was mistaken to think that rights in physical property alleviate scarcity and rights in intellectual property create it ? Information is a scarce good, just like land. Both are commodified - that is, made excludable property in order to create incentives to alleviate their scarcity (pp 20-1, 374).

To the extent that L\&P's argument may be taken to yield any overall sense, it is that, as the creation of scarcity by means of IPs is necessary to give incentives to innovate, Plant is wrong to say this is the creation of scarcity! The necessity L\&P feel to accept the innovation argument leads them to deny the objectionable aspects of that argument which Plant had the intellectual honesty to look in the face. ${ }^{3}$ L\&P's brief rejection of this important position in the analysis of IP is too slight to be taken seriously, but it is expressive of the extent of their sympathy to IP and, we will argue, the unsatisfactory way they maintain it. 
L\&P's other line, not readily reconcilable with the denial that IP rights can usefully be regarded as monopolies at all, is that, though they do tend to create monopolies, this is not really a very serious problem: "we do not mean to suggest that every copyright and every patent should raise warning flags for antitrust enforcers. Most copyrights and patents do not confer enough market power to raise any kind of antitrust issue' ( $\mathrm{p} 15 \mathrm{n}$ 11). The most sustained exposition of the concept of market power in the book concludes that we normally should have 'no worry' ( $p$ 378) about IP in this respect 'because the vast majority of copyrights, patents, and other intellectual property rights confer no more monopoly power on the owner of the right than owning the only barber shop within a five-block radius' (pp 378-9). Even had we the space to do so, we would not wish to go through what L\&P say of these monopoly problems at any length, for the labour would not be repaid. We want only to convey the nature of their attitude to these problems by quoting their treatment of them as they are posed by the 'new economy' ( $p$ 390) based on information technology:

The features of the new economy ... tug it toward monopoly yet, oddly, also toward competition. The more protection from competition a firm that succeeds in obtaining a monopoly will enjoy, the more competition there will be to become that monopolist; and provided that the only feasible or permitted means of obtaining the monopoly are socially productive, this competition may be wholly desirable rather than a form of wasteful rent-seeking. A firm that will have the protection both of intellectual property law and of economies of scale in consumption if it is the first to come up with an essential component of a new economy product or service will have a lucrative monopoly, and this product should accelerate the rate of innovation, just as, other things being equal, the more valuable a hoard of buried treasure is, the more rapidly it will be recovered (p 395).

Well, that's alright then. Similarly, 'provided that' Campbell's dog has feathers instead of fur, then, 'other things being equal' (he also has a beak instead of a muzzle, two instead of four feet, etc), then he is a duck. But, leaving aside the homespun complaisance and absurdity of this passage (and its flat contradiction of the many times L\&P criticise IP as an inducement to rent-seeking, eg p 220), what is so wrong with this way of treating IP rights is that it obscures their essential nature as a public intervention. There certainly are varying degrees of market power, so that if one defines a monopoly by effective market power beyond a certain threshold, there will be interminable argument about whether IP in general or particular IP rights create a monopoly. But the whole point of IP is to strengthen market power by government intervention. When the intervention unarguably purports to create sole rights of supply with the purpose of enhancing market share, gives effect to these rights by state imposition of criminal sanctions foreign to competitive business, or by state enforcement of unusually draconian civil sanctions, and when there may well also be extensive government subsidy of the industries which the intervention is intended to benefit, ${ }^{4}$ it seems to us that it is but natural to call that intervention a monopoly; but we do not want to die in a ditch over this. The most important thing is to recognise that IP is an intervention, and to explore the consequences of this.

\section{IP AS AN INTERVENTION}

An intervention can have only one justification: that the social welfare function is improved by it, and this is, overall, what L\&P believe to be the case with IP. They 
hold that IP encourages 'socially desirable investments', which they define as 'investments that yield social benefits in excess of their social costs' ( $p$ 20). They produce formal models of the welfare calculations necessary to show this for copyright (ch 3), trademarks (pp 174-9), patents (pp 297-300), and trade secrets (p 366), and apply this formal reasoning to subsidiary problems such as the optimal duration (ch 8) and extent (ch 5) of copyright.

The crucial equation in all this modelling is the rather simple one that $\mathrm{W}=\mathrm{W}-$ $\mathrm{e}(\mathrm{z})$, where $\mathrm{W}$ is net welfare, $\mathrm{w}$ is the total welfare provided by granting the IP right, and ' $\mathrm{e}(\mathrm{z})$ is the cost of creating the particular work and is a function of the scope of the [IP] protection' ( $\mathrm{p}$ 80). ( $\mathrm{e}$ is the 'cost of expression' and $\mathrm{z}$ 'the level of [IP] protection' ( $\mathrm{p}$ 71)). As with all cost-benefit calculations, estimating cost in this case is likely to be insuperably difficult but in principle possible. On the other hand, benefit cannot be estimated even in principle if that benefit is, as it is typically claimed to be, the sum of the satisfactions enjoyed by citizens affected by the policy, for data is not available about citizens' preferences regarding goods which, ex hypothesi, do not exist unless the decision is taken to intervene to produce them. (Cost-benefit analysis typically refuses to regard the fact that goods do not exist as expressive of a preference that they should not exist). Hence, benefit estimates are supplied by the modeller in the absence of preference data. In IP, the basic benefit is the accelerated rate of innovation which follows the grant of the IP right.

L\&P follow the overwhelming majority of the IP literature by thinking that they can put realistic values into the algebra which allow them to determine, for example, whether copyright should be extended to unpublished works (pp 131-41). We get the following, entirely characteristic, priceless, result:

An author of unpublished materials is likely to object to their being published because they reveal his disreputable or unethical behaviour. Knowing in advance that copyright protection for such materials was weak might induce him to behave better, thus raising social welfare ? A risk remains that knowledge of discreditable jottings were not protected by copyright would induce people to be more discreet in those jottings. Since the private cost of discretion is likely to be less than its social cost in concealing valuable clues to character, the reticence factor will reduce the consumer surplus generated by biographies if unpublished materials are denied copyright protection (p 141).

On this basis of this airy speculation, models for gauging the welfare consequences of various extensions of copyright are put forward in formal, algebraic terms which the speculation makes ridiculous (pp 131-41, 142-3). We imagine that many of those critical of Posner reading this review will not be surprised at this, for purporting to put objective numerical values on that what cannot be so valued is, of course, what Posnerian law and economics has long been about. ${ }^{5}$

When one puts cost-benefit estimates into practice as policy, one finds what appears so exact on the blackboard has to be turned into rather more rough and ready law, and, of course, the thrust of L\&P's book is that the existing law of IP is capable of being improved upon. Posner has always expressed a pronounced preference for litigation over legislation, but L\&P are in fact broadly sympathetic to both the statute and the case law of IP. The most sustained criticism they make is of the US Visual Artists Rights Act 1990 and the miniscule litigation about moral rights which has followed it (ch 10), and even here the criticism of an unclear (p 286) statute which 
does 'not benefit the group [it] is intended to protect' (p 287), and so has led to a 'paucity' ( $\mathrm{p}$ 286) of questionable (pp 273-4) judgments, is muted.

But statute and case-law of this quality have not always received gentle treatment at Posner's hands. What strikes us about IP law, especially the court judgments, is just how inherently poor it is, with the contradictory necessity of curtailing the rights granted leading to the continual drawing of indefensible distinctions which themselves invite their own criticism. It is all highly reminiscent of what Posner has repeatedly said about the quality of antitrust law, the "vague provisions' (Posner 1976, p 7) of which generally articulate 'meaningless' (Posner 1976, p 59) doctrines which lead only to ‘confusion' (Posner 1979, p 929). Why does the one intervention receive much gentler treatment at L\&P's hands than Posner has been known to mete out to the other?

\section{IP AND THE MARKET}

L\&P are well aware that the innovation argument is essentially the argument for the creation of 'public goods': that the market would produce a sub-optimally low amount of these goods ( $p p$ 19-20), and that intervention is therefore required to produce a higher optimal amount, in the case of IP, a higher optimal rate of innovation. It is on this basis that, to take the famous example to which L\&P themselves refer, that Hotelling (1938) argued for public financing of certain large construction works. But L\&P are anxious to stress that it is better to say that [a good produced under IP protection] has public-good characteristics than that it is a public good' (p 225), for the crucial difference is, of course, that IP is a system of public goods delivered gratis into private hands:

The very term "public good" is misleading ? It sounds like a good produced by the government as opposed to the private sector. That is true of public goods that people cannot be excluded from having the benefit of even if they don't contribute to the cost of supplying the goods. The clearest example is national defence. Many public goods, however, including intellectual property, are excludable in the sense that it is not possible to condition access to them on payment. Such goods need not be provided by the government ( $\mathrm{p} 14)$.

Accepting, if only for the purposes of argument, L\&P's distinction between public goods, and the identification of IP as 'an excludable public good' (p $403 \mathrm{n} \mathrm{3}$ ), we want to concentrate on the important consequence of that distinction. Posner in particular has been known to be somewhat critical of the provision of public goods and the consequent necessity of regulation; indeed, the first paper he wrote, 'Natural Monopoly and Its Regulation' (Posner 1969), was an argument that 'we would be better off without trying to regulate natural monopolies' (Posner 1999, p vi). This paper has had an extraordinary impact, and arguably remains the best thing Posner has written. Public monopolies and public attempts to regulate private monopolies get a pretty thorough drubbing in this paper; but in his subsequent work on IP, the public placing of monopolies in private hands is looked upon, by contrast, very favourably, and the argument against regulation dropped. IP can, for example, readily be regarded as a way of regulating entry to a market, though the regulation seeks to narrow rather than expand entry. The anxiety Posner displayed in 'Natural Monopoly and Its Regulation' to argue that 'Regulation of entry is unjustified and should be abandoned' (Posner 1999, p 82) is precisely what is abandoned in his work on IP. It seems that the 
monopoly which is deplored when the monopoly remains in public hands undergoes a dramatic transformation when the monopoly is granted to a private corporation.

L\&P seem to believe that the only alternative to the growth in IP since 1976 was public ownership of these public goods, and of this they say:

If in 1976 there had been no patent system but instead a system of direct government awards to successful inventors or direct government financing of $R \& D$... if royalties in licenses of intellectual property had been fixed by government rather than by contract; if the publication of books had been a government monopoly; if the prices of books, drugs, and other goods that embody intellectual property were fixed by a regulatory agency; if to minimise access costs intellectual property was given away for free and its costs subsidised by the government - if any of these things had been true, substitution of patent and copyright and trade secret and trademark law, in short of intellectual property rights, would have been a giant step in the right direction from the standpoint of economic efficiency and a major plank of the deregulation movement. But none of these things was true. Intellectual property was already "deregulated" in favour of a property-rights system ( $\mathrm{pp} 414-5$ ).

Well, again, all one can say is that's alright then. It is on the very next page that L\&P tell us, as we have seen, that it 'is uncertain' whether IP since 1976 has 'conferred net benefits' ( $p$ 416), but it is obvious that, so long as the monopoly revenues accrue to private hands, monopolies will be tolerated.

The range of alternatives which L\&P contemplate in the above paragraph is curiously limited. The provision of IP is, in their view, as in the view of the great majority of those writing on the subject, a matter of either a private or public monopoly. Posner and Landes are, indeed, in advance of much of the literature in giving extended consideration to the latter. But surely it is puzzling that they, of all writers, do not consider the alternative of market provision, for they do not think it possible that 'such property would be created in a free-market system' ( $p$ 376) (save for trivial exceptions). In an entirely characteristic passage they say:

In the absence of intellectual property rights either the intellectual property will not be created or the government may have to finance it through a system of grants or rewards to writers and inventors. (We say "may", not "will", because there may be alternative sources of funding, such as private patronage.) (p 24).

There are two errors which inform this passage. The first is to ignore the possibilities of alternative, competitive business models as the basis of innovation, albeit ones which no doubt will lead to a typically lower rate of some kinds of innovation than is produced by the stimulus of the grant of the IP monopoly. The second is to assume that, when innovation does not take place absent the IP monopoly, this is always sub-optimal. But one does not have to be a Luddite to see that the rate of innovation cannot be assumed to be invariably positively correlated to welfare. One merely has to be other than fixated with growth of gdp to see this. What is more, the lower rate of innovation absent the IP intervention would be the rate produced by the market, even if this meant that the good produced under IP was not produced, and it is most curious to find L\&P not giving any weight, indeed barely any recognition, to the market's verdict that a good should not be produced because its production will not yield revenues in excess of the costs of its production. ${ }^{6}$ Normally, 
when this is the case, (neo-)liberal economists conclude it is welfare optimising that the good is not produced, and question interventions which seek to produce it as a public good. But L\&P clearly believe IP to be the acceptable face of intervention, and we can put this down only to the fact that IP monopolies are conferred upon private parties, not upon public undertakings.

The most substantial defence of market allocation of the goods which now are allocated through IP rights is that of Plant which we have mentioned above. L\&P discuss Plant in their general consideration of the issues in their 'Introduction' and in

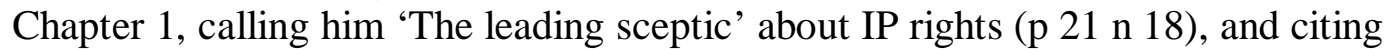
him as authority for raising the question whether 'the high social costs of intellectual property rights create uncertainty as to whether on balance such rights are, from an overall social standpoint, cost-justified at all' ( $\mathrm{p} 21)$. They purport to take from Plant the argument that 'intellectual property protection might result in too much intellectual property being produced rather than too little (or perhaps both, for different types of intellectual property)' ( $p 22$ ), and repeatedly cite him when they argue that present arrangements are inefficient in that they lead to one or other of these errors (e.g. p 374). But this is not what Plant means when he hazards the possibility that 'there may be too much invention' (Plant 1974, p 55). What Plant means is that there is no way of determining the optimal rate of innovation for an economy, and therefore we cannot have confidence in claims to be able to maximise the social welfare function by the intervention of creating or curtailing IP rights, regardless of whether the argument is that there is too little, just enough, or too much protection, for the necessary quantities cannot be known. If one cannot know these things, it is unwise to throw the great weight of state intervention backed by compulsion behind a particular position which cannot be known to be right and certainly will have costs and lead to rent-seeking. It is better to leave things to decentralised, voluntary allocations through the market, which will be crowded out by IP monopolies (Merges 1994).

L\&P seem incapable of understanding Plant's argument, and they repeatedly note aspects of it which should cause them to pause for thought, but, having noted, move on. In a typical fashion, they also cite Hayek making very similar points ( $p$ 415), but again do not stop to learn from Hayek by pursuing those points. Even more strikingly, in the context of discussing the foundations of the theory of public goods, they, seemingly approvingly, cite Coase's (1946) criticism of the concept of marginal cost that has played such a role in justifying intervention, which is that one cannot know what marginal costs are for the purposes of marginal cost pricing (p 23). Nevertheless, their entire book is an attempt to set an optimal level for the marginal revenues of the holders of various IP rights. L\&P are even prepared to acknowledge that 'the empirical studies required' for proper identification of when it is necessary to grant IP rights to avoid the rate of innovation being 'seriously suboptimal' are not available and (if we read them aright) cannot be made available (p 24), but proceed regardless. In a throwaway line that one can hardly believe one is reading, they juxtapose the argument they take from Plant that the rate of innovation may be too high with an argument they take from Arrow (1985, ch 4) that (for reasons we need not set out) it may be too low, and of this they say: 'Unfortunately, the weights of these two offsetting factors are unknown' (p 304). In sum, L\&P tell us that 'Economic analysis has come up short of providing either theoretical or empirical grounds for assessing the overall effect of intellectual property law on economic welfare' ( $p$ 422). We recall that L\&P began their book by warning us that 'economic analysis of intellectual property remains inconclusive, if not indeterminate' (p 10). Now, whilst it 
certainly is the case that they intentionally and, even more, unintentionally show this to be so, one does have to wonder what they therefore think the justification of their book can be. Their claim that what they show of IP law amounts to an 'economic structure' is an unintended parody of 'structure', or 'IP', or both.

In truth, behind the equivocations they repeatedly enter, L\&P remain unthinkingly confident they that they can determine a social welfare function from which to judge the outcomes of IP intervention. It is important to stress that sort of intervention, rather than market allocation, is what Posnerian law and economics is all about (Campbell 1994, pp 445-9). ${ }^{7}$ Wealth maximisation is a sort of welfare economics, but a sort which has 'economic' 'efficiency', rather than any of the more left-wing sounding goals normally identified with welfare economics, as its end. It has proven impossible to say what wealth maximisation is in any theoretically coherent way. There seems to be no point saying more than that it represents the growth of private accumulation. The goal of wealth maximisation is not a fully competitive market, in which costs as well as profits are internalised, but a state of private accumulation in which the law is efficient to the extent that it is used to maximise private accumulation, even if, as is certainly the case with regard to IP, this involves

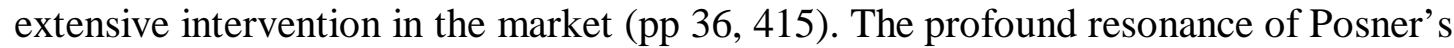
work lies in the fact that this is, of course, an empirically accurate description of the role of the state in advanced capitalism, and the weakness of that work is that this is defended not as the intervention it is, but as 'the market'.

All this harks back to the tortured interpretation of Pareto optimality that brought Posner to such prominence a quarter of a century ago. What the book under review contributes to the wealth maximisation literature is new evidence of just how much of a reformulation 'market', 'competition', etc undergo in Posnerian law and economics:

Casual talk about patent and copyright "monopolies" ... implicitly views competition as the state in which there are many firms competing to sell the same product rather than as the state in which society's scarce resources are being exploited as efficiently as possible. From the latter standpoint, which is more directly related to economic welfare, excluding others from the use of property either physical or intellectual may be procompetitive even if the result is a reduction in the number of competitors or a divergence from perfect competition ... If making intellectual property excludable creates value, the efficient allocation of resources may be improved even if an economic and not merely a nominal legal monopoly is created ( $\mathrm{p} 379$ ).

The Posnerian touch ${ }^{8}$ is not that non-competitive outcomes are regarded as welfare optimising without any defence of how one would know this, for this is characteristic of the IP literature. It is that these outcomes are called competitive, when this is exactly what they are not. This passing off of 'intervention' as 'market' is the very essence of the Posnerian defence of 'economic efficiency'.

\section{ONE ALTERNATIVE TO IP: RIGHTS TO REMUNERATION}

The major defect in the 'structure' of IP which L\&P have erected on such shaky foundations is that they fail to consider alternative approaches towards providing rewards for innovation, especially more market-based approaches. The need for this has been recognised by other law and economics scholars, notably Kitch, who identifies both the 'failure to consider the importance of licensing' and the 'failure to 
consider the full range of policy variables' as two of four 'elementary and persistent errors in the economic analysis of IP' (Kitch 2000). ${ }^{9}$ We would also add the neglect of the remedies for infringement, which we have mentioned are not discussed in L\&P's book. L\&P fail to directly or systematically address these issues, no doubt because to do so would both require them to abandon the assumption that innovation must be encouraged by property rights formed on the basis of the innovation argument, as well as taking them further into the thicket of the complexities of IP law and practice than they would find it comfortable to go. Proper discussion of the panoply of draconian IP remedies, which now, of course, has added the public shaming of children to the incarceration of adults, would be a particularly rough ride.

Much IP scholarship has pointed to the disadvantages of protecting innovation in the form of exclusive private property rights. In practice, the valorisation of IP rights results from the sales of products which very often embody a multiplicity of those rights, frequently with different owners: for example, a multi-media product such as a DVD, which will combine music, lyrics, visuals and software; and biomedical products, which often depend on a variety of building blocks (Eisenberg 2001). Granting each IP owner an exclusive right may create significant obstacles in the form of transaction costs for bargaining over these rights. It also produces some of the most deleterious effects of IP rights, such as defensive patenting to block off a competing technology. L\&P discuss these problems (eg pp 310-26), but, characteristically, their discussion merely serves to relegate these problems to the sidelines and does not prevent them sticking to the innovation argument.

A very different economic analysis from L\&P's has been made by Shavell and van Ypersle (2001), who argue that a superior approach to the private property right would be a reward system, which they suggest could be based on sales data, and if done continuously would be based on superior information than that available to the innovator who normally has to estimate the value ex ante. L\&P dismiss such suggestions, as well as those for compulsory licensing, as 'hopelessly politicized', without any further consideration ( $\mathrm{p} 9$ ). Yet careful analysis of the factors that should affect optimal design of rights over innovation points to their close connection with the ease of contracting over such rights (Gallini and Scotchmer 2002).

As we have suggested elsewhere (Picciotto and Campbell 2003), a strong case can be made for treating IP not as an exclusive property right, but a right to remuneration. This argument has been made in particular by Jerome Reichman, although he has limited it to incremental innovations which in his view do not merit the protection of full property rights (Reichman 2001). The creation of what would be in effect rights to use innovations, subject to acknowledgement and payment of appropriate fees, would, in our view, do much to redress the balance between appropriation and diffusion which many, including even L\&P, consider has been weighted far too heavily in favour of exclusivity. Bargaining over the price and other terms of access would take place in a decentralised way in the shadow of this law, but since the legal remedy would be less stringent, the outcome would be less tightly prescribed (in favour of the IP rights holder). ${ }^{10}$

\section{CONCLUSION}

One is tempted to say that the shortcomings of L\&P's book are the result of the way it was composed: largely a stitching together of articles produced over almost twenty years. But, if the underlying argument is sufficiently sound, then, with adequate revision, there is no need for this way of writing to lead to such a disjointed or even incoherent end-product. Posner's early, popular book on antitrust, for example, makes 
a far better job of this (Posner 1976, pp vii-viii), and even his (and Easterbrook's (1981)) casebook on antitrust reads more coherently than the book under review. One is obliged to note that the revision that has produced this book has not been adequate, for how else can one account for the repeated presence of flatly contradictory statements within paragraphs of each other? But the incoherence of the book is more, we believe, the result of the lack of soundness of its underlying argument. L\&P wish to defend the innovation argument for IP, but no at all competent scholar can now do so without difficulty, for the necessity of curtailing the IP rights granted on the authority of the innovation argument is now what is most obvious to independent scholars (as opposed to IP lobbyists and practitioners).

The theoretically progressive thing to do in the light of this is acknowledge the shortcomings of the innovation argument and seek extensive improvement upon it. L\&P instead enter an overwhelming number of exceptions, indeed congratulate themselves on having the acuity to do so, but maintain the basic argument intact. They do so despite the fact that IP, whether one calls it a system of monopolies or not, is a system of government intervention designed to alter what would otherwise be the results of market allocation, something about which one might have thought they would feel uncomfortable The small discomfort that they actually seem to experience surely is yet further evidence that Posnerian wealth maximisation has very little indeed to do with encouraging markets and everything to do with organising state subsidy of private accumulation.

But the, as it were, right-wing error of approving copyright legislation which the entertainment corporation is bound to capture, or patent regulation the agribusiness and pharmaceutical corporation is highly likely to capture, etc, has a complementary left-wing error. The entire western marxist tradition was a critique of the degradation of culture produced by the corporate sales effort, ${ }^{11}$ and in a strong sense this was right. But this is a critique of 'the market', and so western marxism had had little power to relate its critique to specific institutions, largely degenerating into a sort of intellectual crie de coeur against the vulgarity of the choices of masses in the grip of false consciousness. But the 'culture industry' against which western marxism railed is a system of monopolising interventions by the state at the behest of inter alia the organised lobbying of capitalist corporations, ie it is not a market at all but its opposite; and this really is rather beyond the comprehension of most left-wing critiques of corporate capitalism.

We are here presented with a characteristic feature of the economic policy, and therefore the politics, of corporate capitalism. The most apparently antithetic left and right-wing positions are united in their commitment to the belief that the state can directly produce optimum outcomes, and their struggle being not over means but ends, there is a surprising degree of consensus about means. The inevitable result is a growth in the size and power of the state. In the course of this, the anarchist and libertarian strains that are the highest aspirations of left and right-wing politics are put off to the indefinite future and the work of policy now is to get hold of the state and use it.

It is not ultimately to the credit of left-wing politics that the contradictions of IP are greater for the right. L\&P have spent their intellectual lives decrying intervention, but evidently not when corporate capitalism can find valuable use for it in the pursuit of accumulation, for this is wealth maximisation. The desperate tension in Posner's version of law and economics between the freedom central to the concept of choice and the oppression central to making sure those choices maximise wealth as he understands it is nowhere more clear than in L\&P's views of intellectual property, in 
which even monopolies redolent of mercantilism are viewed positively so long as they maximise corporate revenue. L\&P have given us the benefit of their views on more or less everything already. There is only one subject about which they could write and make more clear the bias that is the central feature of their work in general, and their work on IP in particular: arms spending by the military-industrial complex.

\section{NOTES}

${ }^{1}$ A review of WM Landes and RA Posner, The Economic Structure of Intellectual Property Law, Cambridge, Mass, Belknap Press of Harvard University Press, 2003, pp vi, 442, ISBN 0-674-01204-6, hbk, US\$39.95. Unattributed page references are to this book. An earlier version of this review was read to the Annual Conference of the Canadian Law and Economics Association, University of Toronto, Canada, September 2004. We should like to thank Ronan Deazley for his comments on this review.

${ }^{2}$ There are many passage in this book which outright contradict this, for, as L\&P themselves say, 'we have seen throughout this book' that intellectual property rights and 'physical property rights' do not have 'identical economic properties' (p 414), that government has a 'much deeper involvement in intellectual than in physical property' ( $\mathrm{p} 36$ ), and, in sum, that it is 'perilous to extrapolate' from physical property to IP (p 36). It is fruitless to chase through all the statements of this sort, from which an unsympathetic critic would conclude that this book is just overall incoherent.

${ }^{3} \mathrm{We}$ do not wish to imply that Plant is alone. In the recent scholarship, contrast L\&P to eg Kaplow (1984, p 1817): 'A practice is deemed to violate the antitrust law because it is anticompetitive. But the very purpose of the patent grant is to reward the patentee by limiting competition, in full recognition that monopolistic evils are the price society will have to pay'.

${ }^{4}$ A high proportion of R\&D is publicly funded. According to the $\operatorname{OECD}(2004, \mathrm{p} 70)$ data, $30 \%$ of R\&D is financed by governments; while $7 \%$ (in the US closer to $10 \%$ ) 
of industry spending on R\&D is directly paid for by government (ie this does not include tax and other incentives). In addition, a high proportion of goods based on IP are price-regulated, notably pharmaceutical drugs which are purchased by state or insurance-funded healthcare systems.

${ }^{5}$ It is only relatively recently that Posnerian law and economics has turned its attention to the defence of cost-benefit analysis that Posnerian law and economics requires (Posner 2000). Nothing of substance seems to us to have been added to the vast existing literature on cost-benefit analysis in welfare economics, public administration, policy analysis, etc.

${ }^{6} \mathrm{We}$ feel obliged to give an example so that the non-specialist reader may follow our reasoning, but this is a merely illustrative example which we pick because it suits our argument well. The leading work on the relationship of IP and antitrust, to which L\&P refer (p 372 n 1), is Hovenkamp et al (2004), which uses the following example to illustrate the innovation argument (Hovenkamp et al 2002, para 4.1.c): 'Making (the James Cameron film) Titanic may have cost $\$ 150,000,000$ ', and though it 'can presumably be duplicated onto a video cassette for a cost of $\$ 2$ per copy', it is essential that we convey 'very high market power' by means of copyright upon its owners so that they can charge $\$ 20$ per copy, otherwise they will not be able to recover their fixed and marginal costs and make a profit. We must make it plain that we believe that Titanic is dreadful rubbish, and that the film industry in particular and culture in general would be better without this sort of stuff, but the point is that intervention should not be put on a basis where differences of opinion of this nature are at all to the point. Can we be so sure that the making of Titanic, and all it implies about film, celebrity, advertising, etc, so optimises the social welfare function that it 
justifies IP intervention? Can we be sufficiently confident about this that we should trump the market's verdict that investments of this nature in Hollywood blockbusters should not be made (unless at a private investor's hazard when faced with competition over diffusion)?

When this paper was presented to the Canadian Law and Economics Society, a member of the audience seemed to accept the point but asked "what about Citizen Kane?' Three things might be said: (1) in our opinion, exactly the same point applies regardless of the merit of the film; (2) a specific case for the production of Citizen Kane might be made which would need to establish its superiority to Titanic. This would be a specific case for public support (perhaps more like a patent), rather then the block support presently granted by copyright. (The incorrigibility of this argument and its authoritarian implications are why we prefer (1) to (2)); and (3) after Citizen Kane, Welles never again enjoyed a really productive relationship with Hollywood, which repeatedly denied him finance. Now, Welles was not blameless in this, but a system of finance based on copyright that privileges pursuit of very high volume sales by mass marketing of IP protected brands was more to blame. A system that denies adequate funds to Orson Welles but gives them in superabundance to James Cameron cannot easily be said to be part of the solution rather than part of the problem.

Since this was submitted for publication, we have learned of a fourth point that might be made. Weber $(2004$, p 6) tells us that the special effects that are the only other than contemptible part of Titanic were created using Linux, which is, of course, open source software! The great success of Linux so contradicts the innovation argument that it has been called 'the impossible public good' (Kollock 1999, p 230). 
${ }^{7}$ The description of Posner's relationship to Coase in this paper is quite wrong, and was hopefully corrected in later work (Campbell 1996).

${ }^{8}$ So far as we are aware, the first to apply the Chicago School approach to IP in this way was not Posner but Bowman, whose 1973 Patent and Antitrust Law turned on his belief that both policies aimed 'to maximise wealth by producing what consumers want at the lowest cost' (p 1).

${ }^{9}$ Kitch (2000, pp 1734-5) used earlier work by L\&P to illustrate another such error and they respond to him in the book under review ( $\mathrm{pp} 375-7$ ).

${ }^{10}$ Unfortunately, of course, this approach is substantially precluded by the farreaching impact of the Agreement on Trade Related Property Rights (hereinafter TRIPS) administered by the World Trade Organisation. Nevertheless, the extent and efficacy of IP remedies, as well as the regulation of licensing, are central policy questions to be negotiated under the aegis of the TRIPS agreement.

${ }^{11}$ The leading figure is, of course, Adorno, and a useful collection of his papers on the theme is Adorno (1991).

\section{BIBLIOGRAPHY}

Adorno, TW (1991) The Culture Industry. London: Routledge Arrow, KJ (1985) Production and Capital (Collected Papers, vol 5). Cambridge, MA: Belknap Press Bowman, WS (1973) Patent and Antitrust Law. Chicago, Ill: University of Chicago Press

Campbell, D (1994) 'Ayres Versus Coase: An Attempt to Recover the Issue of Equality in Law and Economics', Journal of Law and Society 21: 434 Campbell, D (1996) 'On What is Valuable in Law and Economics', Otago Law Review 8: 489

Campbell, D and Picciotto, S (1998) 'Exploring the Interaction Between Law and Economics: The Limits of Formalism', Legal Studies, 18: 249

Coase, RH (1946) 'The Marginal Cost Controversy', Economica (ns) 13: 169 Dreyfuss, RC et al (eds) (2001) Expanding the Boundaries of Intellectual Property. Innovation Policy for the Information Society. Oxford: Oxford University Press Eisenberg, RS (2001) 'Bargaining over the Transfer of Proprietary Research Tools: Is this Market Failing or Emerging?' in Dreyfuss et al (eds) 
Gallini, N and S Scotchmer (2002) 'Intellectual Property: When Is It the Best Incentive System?' Innovation Policy and the Economy 2: 51

Hotelling, H (1938) 'The General Welfare in Relation to Problems of Taxation and of Railway and Utility Rates', Econometrica 6: 242

Hovenkamp, H (2004) IP and Antitrust. New York: Aspen Publishers

Kaplow, L (1984) 'The Patent-Antitrust Intersection: A Reappraisal', Harvard Law

Review 97: 1815

Kitch, EW (2000) 'Elementary and Persistent Errors in the Economic Analysis of Intellectual Property', Vanderbilt Law Review 53: 1727

Kollock, P (1999) 'The Economics of Online Co-operation: Gifts and Public Goods in Cyberspace', in MA Smith and P Kollock (eds) Communities in Cyberspace. London: Routledge, 220

Lakatos, I (1978) The Methodology of Scientific Research Programmes (Collected Papers, vol 1). Cambridge: Cambridge University Press

Landes, WM and Posner, RA (1987) The Economic Structure of Tort Law.

Cambridge, Mass: Harvard University Press

Merges, RP (1994) 'Of Property Rules, Coase, and Intellectual Property’, Columbia

Law Review 94: 2655

OECD (2004) OECD in Figures 2004. www.oecdbookshop.org

Picciotto, S and Campbell, D (2003) 'Whose Molecule Is It Anyway? Private and

Social Perspectives on Intellectual Property', in A Hudson (ed), New Perspectives on

Property Law: Obligations and Restitution. London: Cavendish, 279

Plant, A (1974) Selected Economic Essays and Addresses. London: Routledge and

Kegan Paul

Posner, RA (1969) 'Natural Monopoly and Its Regulation', Stanford Law Review, 21:

518

Posner, RA (1976) Antitrust Law: An Economic Perspective. Chicago, Ill: University of Chicago Press

Posner, RA (1979) 'The Chicago School of Antitrust Analysis', University of

Pennsylvania Law Review 127: 925

Posner, RA (1999) Natural Monopoly and Its Regulation: 30th Anniversary Edition, Washington DC: Cato Institute

Posner, RA (2000) 'Cost-benefit Analysis: Definition, Justification and Comment on Conference Papers', Journal of Legal Studies 29: 1153

Posner, RA and Easterbrook, FH (1981) Antitrust, 2nd. edn. St. Paul, Minn: West

Publishing

Reichman, JH (2001) 'Of Green Tulips and Legal Kudzu: Repackaging Rights in Subpatentable Innovation', in Dreyfuss et al (eds)

Shavell, S and van Ypersele, T (2001) 'Rewards versus Intellectual Property Rights', Journal of Law and Economics 44: 525

Stevenson, CL (1938) 'Persuasive Definitions', Mind 47: 331

Weber, S (2004) The Success of Open Source. Cambridge, MA: Harvard University Press 